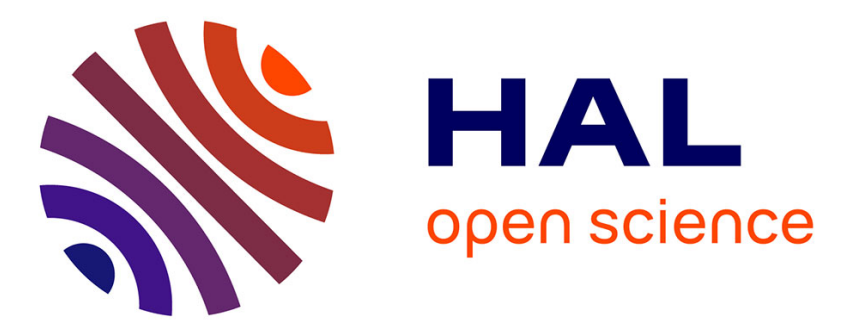

\title{
Study of the aggregation of undecylammonium chloride in presence of sodium chloride using small angle neutron scattering
}

E. López-Cabarcos, A. de Geyer, P. Galera Gómez

\section{- To cite this version:}

E. López-Cabarcos, A. de Geyer, P. Galera Gómez. Study of the aggregation of undecylammonium chloride in presence of sodium chloride using small angle neutron scattering. Journal de Physique IV Proceedings, 1993, 03 (C8), pp.C8-205-C8-210. 10.1051/jp4:1993840 . jpa-00252271

\section{HAL Id: jpa-00252271 \\ https://hal.science/jpa-00252271}

Submitted on 1 Jan 1993

HAL is a multi-disciplinary open access archive for the deposit and dissemination of scientific research documents, whether they are published or not. The documents may come from teaching and research institutions in France or abroad, or from public or private research centers.
L'archive ouverte pluridisciplinaire HAL, est destinée au dépôt et à la diffusion de documents scientifiques de niveau recherche, publiés ou non, émanant des établissements d'enseignement et de recherche français ou étrangers, des laboratoires publics ou privés. 


\title{
Study of the aggregation of undecylammonium chloride in presence of sodium chloride using small angle neutron scattering
}

\author{
E. LÓPEZ-CABARCOS, A. DE GEYER and P.A. GALERA GÓMEZ
}

Dept. Química-Física Farmacéutica, Facultad de Farmacia, 28040 Madrid, Spain

* Institut Laue-Langevin, Grenoble, France

Small-angle neutron scattering (SANS) measurements have been made to estimate the shape and size of Undecylammonium Chloride (UAC) micelles in deuterated water in the presence of $\mathrm{NaCl}$ at two ionic strengths. For the lowest ionic strength the structure factor has been determined from the Percus-Yevick approximation in the form given by Ashcroft and Leckner. The aggregation number increases with increasing the UAC concentration and its value, in all cases, is larger than that obtained from light scattering. The SANS data obtained at the highest ionic strength are consistent with the formation of large aggregates with rod-like structure.

\section{INTRODUCTION}

In an early work (1) we have studied the aggregation of undecylammonium chloride (UAC) in aqueous solutions of $\mathrm{NaCl}$ at several concentrations of this salt using light scattering. We found that the degree of dissociation of the micelles of UAC is low and large micelles are formed. Furthermore, the aggregation number of UAC is much more markedly dependent on the added salt concentration than are those for some other cationic and anionic surfactants (2-4). However, the homologue dodecylammonium chloride (DAC), shows a similar behaviour to UAC (5) and its aggregation number in water presents a prominent change on the surfactant concentration (6).

We report here saNs data obtained on UAC solutions which complement previous results obtained with light scattering (1) and viscometry (7). 


\section{EXPERIMENTAL}

Undecylammonium chloride was obtained by passing gaseous hydrogen chloride through a solution of the undecylamine in ethyl ether. The resulting white precipitate was washed several times with ethyl ether and vacuum dried overnight. The $\mathrm{NaCl}$ from Merck was heated at $300^{\circ} \mathrm{C}$ for $3 \mathrm{~h}$ prior to use.

The sANS measurements were performed at the Institute Laue-Langevin, using the diffractometer D17. Standard quartz cells, thermostated at $25{ }^{\circ} \mathrm{C}$, were employed. The measurements were carried out using sample to detector distances of 1.4 and $2.8 \mathrm{~m}$ and neutron wavelength of $1.2 \mathrm{~nm}$.

The data were reduced to the radial average scattering intensity, I(Q), as a function of $Q(=(4 \pi / \lambda) \sin (\theta / 2)$ with $\theta=$ the angle between the incident and scattered beams) using standard ILL programs.

SANS ANALYSIS

The aggregation number, $g_{w}$, in these systems is too high to be consistent with a spherical shape (1). The observed scattered intensity of neutrons at a scattering vector $\mathbf{Q}$ for monodisperse interacting and symmetrically spherical micelles can be given as a product of the single particle scattering function $P(Q)$ and the structure factor $S(Q)(4,8)$ and is written,

$$
I(Q)=\left(\rho_{1}-\rho_{s}\right)^{2} V_{1}^{2} N_{P} P(Q) S(Q)
$$

where $\rho_{1}$ is the coherent scattering-length density of the micellar core of volume $V_{1}$ and $\rho_{s}$ is the coherent scattering length density of the solvent, and $N_{p}$ is the number of micelles per unit volume. The above equation is suitable for one-shell micelle model. In the $I(Q)$ calculations we got the best fit to the experimental data using a prolate ellipsoidal shape (8) for the evaluation of the $P(Q)$.

A useful model for repulsive interactions among particles in order to interpret the $S(Q)$ against $Q$ data is the hard sphere model, based in the idea of the hard-sphere potential. For ionic micelles, this model, suggests that the particle has an effective radius $R_{\text {eff }}$ which is larger than the micellar equivalent radius $R_{m p}(9)$. For a prolate ellipsoid $R_{m p}=\left[\left(a l_{c}^{2}\right)^{1 / 3}+1_{b}\right]$, where $a=$ the larger ellipsoid semi-axis length, $1_{c}=$ the shorter ellipsoid 
semi-axis length and $l_{h}=5 \dot{A}$ is the length of the ammonium group. If we regard the micelle with the electric double layer as a hard sphere, its effective radius should be a quantity close to the micellar radius $R_{m p} p l u s$ the Debye-Hückel double layer length $\kappa^{-1}$. The effective radius is then expressed in the form,

$$
R_{e f f}=R_{m p}+\frac{1}{\kappa}+\delta
$$

$\delta$ is a fitting parameter, which account for some of the approximations involved in this model. Thus, the micelles occupy an effective volume fraction given by

$$
\varphi_{e f f}=\frac{4}{3} \pi R_{e f f}^{3} N_{p}
$$

A simple expression for $S(Q)$ is obtained from the Percus-Yevick (10) approximation in the form given by Ashcroft and Lekner (11) as,

$$
S(Q)=\left[1-N_{p} C\left(2 Q R_{e f f}\right)\right]^{-1}
$$

with

$$
C\left(2 Q R_{e f f}\right)=-32 \pi R_{e f f}^{3} \int_{0}^{1} \frac{\sin \left(2 s Q R_{e f f}\right)}{2 s Q R_{e f f}}\left(\alpha+\beta s+\gamma s^{3}\right) s^{2} d s
$$

where $\alpha, \beta$ y $\gamma$ are defined as,

$$
\begin{gathered}
\alpha=\left(1+2 \varphi_{e f f}\right)^{2} /\left(1-\varphi_{e f f}\right)^{4} \\
\beta=-6 \varphi_{e f f}\left(1+0.5 \varphi_{e f f}\right)^{2} /\left(1-\varphi_{e f f}\right)^{4} \\
\gamma=0.5 \varphi_{e f f}\left(1+2 \varphi_{e f f}\right)^{2} /\left(1-\varphi_{e f f}\right)^{4}
\end{gathered}
$$

\section{RESULTS AND DISCUSSION}

Two different patterns for $I(Q)$ vs $Q$ has been obtained depending on the ionic strength.

Diluted solution of NaCl. When the ionic strength is low, i.e., [NaCl] $=0.043$ mol $/ \mathrm{dm}^{3}$, the scattered intensity has been calculated according to the model described in precedent section. Eq. [1] in this case takes the following form 
At this Nacl concentration, the CMC is $C_{0}=193.4 \mathrm{mM}$ (1). The calculated spectrum and the experimental results are present in Fig.1 for the various surfactant concentrations assayed.

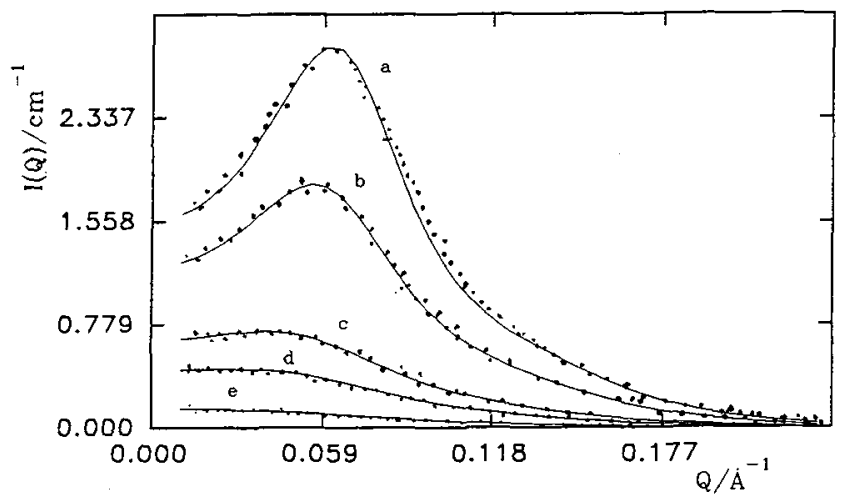

Figure 1. Calculated spectrum (lines) and experimental results (dots) for UAC in $\mathrm{D}_{2} \mathrm{O}$ with $0.0428 \mathrm{M}$ of $\mathrm{NaCl}$ at various surfactant concentrations : (a) 145.2 , (b) 97.3, (c) 48.2 , (d) 36.4 , (e) $24.3 \mathrm{mmol} / \mathrm{dm}^{3}$

Figure 2. Dependence of $g_{w}$ with the surfactant concentration

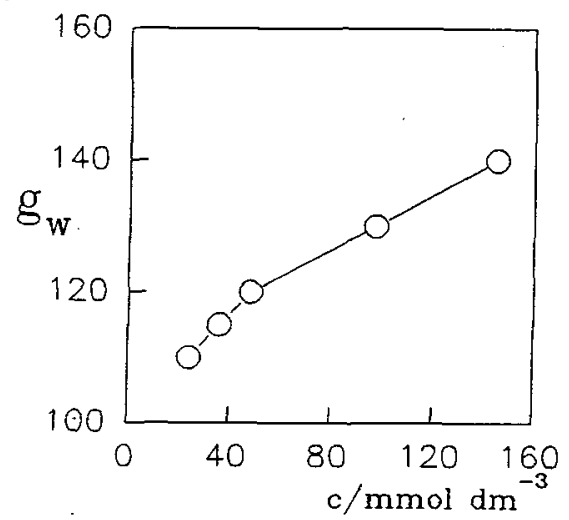

The concentration dependence of $g_{w}$ is shown in Fig.2 The aggregation number increases with increasing the surfactant concentration. The value of $(1 / k+\delta)$, which represent the length of the layer outside the micelle excluded for the gurfactant ions and co-ions, increases as the surfactant concentration decreases. The length of this layer for largest surfactant concentration is $13.2 \dot{A}$. This value is close to the Debye-Hückel double layer length, $1 / x=12.2 \AA$. For the smallest surfactant concentration the length of this layer is $18.2 \dot{A}$. These results indicate that the effective micellar charge is small and increases with decreasing the surfactant concentration. The aggregation number obtained from light scattering for UAC in NaCl at the 
above ionic strength is $g_{w}=62$. This value is gmaller than that obtained from SANS where this parameter ranges from 140 to 110 ( Fig.2). The difference may be justified, in part, from the increase of $g_{w}$ as the surfactant concentration is increased. The value of $g_{w}$ obtained from light scattering is a quantity extrapolated at the CMC, thus it must be equal or smaller than that obtained from SANS. However, the aggregation number found from SANS in our systems is rather large. On the other, hand viscosity data also indicates an increase in the aggregation number with the surfactant concentration (7). Large micelles are presumably polidisperse and therefore the scattered intensity should increase due to this factor and the results obtained from Eq [1] would be approximate.

Concentrated solution of $\mathrm{NaCl}$. The results obtained in the form of $I(Q)$ against $Q$ curves are shown in Fig. 3

Figure 3 scattering patterns for UAC in $\mathrm{D}_{2} \mathrm{O}$ solutions of $\mathrm{NaCl} 0.34 \mathrm{~mol} / \mathrm{dm}^{3}$ at various surfactant concentrations: (a) 6.5 , (b) 29.1 , (c) 48.2 , (d) $72.7 \mathrm{mmol} / \mathrm{dm}^{3}$.

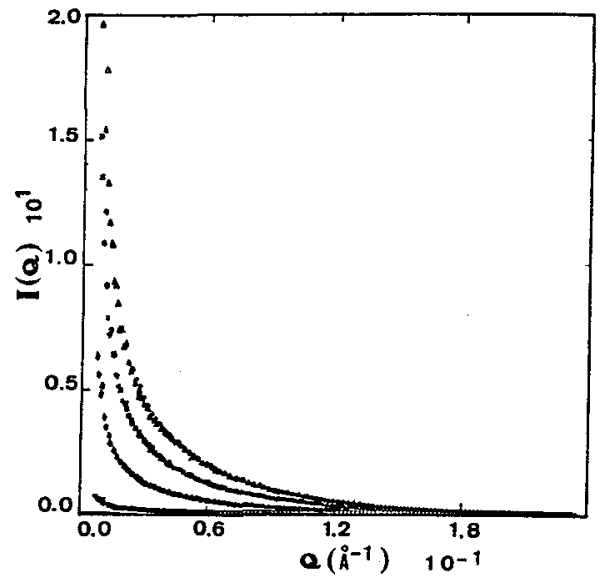

In these cases, the micelle charge is screened and the surfactant concentration is low and one can adopt $S(Q)=1$. Assuming rod-like particles, the scattered intensity can be written in the form (12),

$$
I(Q)_{G}=N_{p} L(\pi / Q)\left(\rho_{1}-\rho_{s}\right)^{2} A^{2} \exp \left(-Q^{2} R_{c}^{2} / 2\right)
$$

where $A=$ the crossectional area of the particle, $L=$ the length of the cylindrical micelle and $R_{c}=$ the radius of gyration of the crossectional area of the micelle. 
Figure 4 scattering curves for UAC in the appropriate representation for rods. The linear behaviour observed suggests that the micellar unit is rod-like type. The above equation has been used to determine

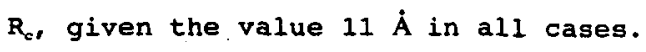
Thus, the radius for the cylindrical

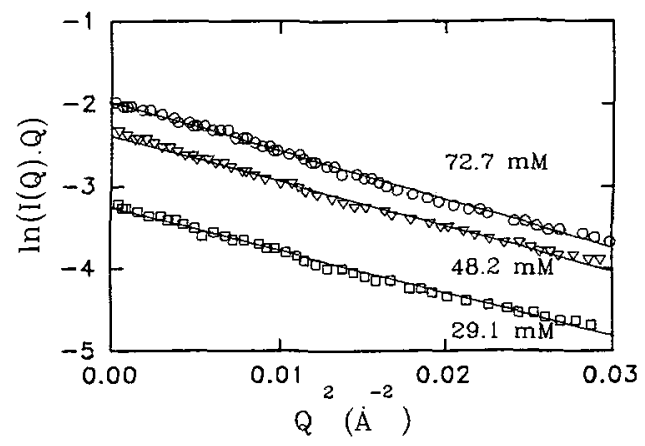
micelle, $R\left(=2^{1 / 2} R_{c}\right)$, is equal to $15.6 \dot{A}$ and gives a good agreement with the length of the fully stretched undecyl chain $I_{c}=15.4 \dot{\mathrm{A}}$.

\section{ACKNOWLEDGEMENTS}

The authors gratefully acknowledge support from the DGICYT (PB91-0355) and La Consejería de Educación y Cultura de la Comunidad de Madrid (284/92).

\section{REFERENCES}

1.- González-Ayesta, T., and Galera-Gómez, P.A., J. Colloid Interface sci. $153,73,(1992)$

2.- Huisman, H. F., Proc. K. Ned. Akad. We. Ser. B 67, 367, 376, 388, 407 (1964)

3. Corti, M., and Degiorgio, V.M., J.Phys. Chem. 85, 711 (1981)

4.- Hayter, J.B. and Penfold, P., Colloid Polym. Sci.261, 1022 (1983).

5.- Kushner, L.M., Hubbard, W. D., and Parker, R. A., J. Res.NatI. Bur.Stand. 59, $113(1957)$

6.- Malliaris, A., Lang, J., and Zana, R., J.Colloid and Interface Sci. 110, $237(1986)$

7.- González-Ayesta, T., and Galera-Gómez, P.A., J. Colloid Interface Sci. (in press)

8.- Sheu, E. Y. Wu, C. F., and Chen, S.H., J. Phys. Chem. 90, 4179, (1986).

9.- Cebula, D.J. Goodwing, J. W., Jeffrey, G.C., Ottewill, R., Parentich, A., Richarson, R.A., Faraday Discuss. Chem. Soc., 76, 37 (1983).

10.- Percus, J.K. and Yevick, G.J., Phys. Rev., 110,1 (1958).

11.- Ashcroft, N.W., and Lekner,J., Phys. Rev.,145, 83 (1966).

12.- Glatter, 0., Krattky, 0., Small Angle X-ray Scattering. Academic Press. London (1982) 